\title{
Asthenospheric flow and origin of volcanism in the Baikal Rift area
}

\author{
Sergei Lebedev ${ }^{\mathrm{a}, *}$, Thomas Meier ${ }^{\mathrm{b}}$, Rob D. van der Hilst ${ }^{\mathrm{a}, \mathrm{c}}$ \\ ${ }^{a}$ Utrecht University, Department of Earth Sciences, Budapestlaan 4, Utrecht, 3584 CD, the Netherlands \\ ${ }^{\mathrm{b}}$ Ruhr University Bochum, Department of Geology, Mineralogy and Geophysics, Bochum 44780, Germany \\ ${ }^{\mathrm{c}}$ MIT, EAPS, 54-522, Cambridge, MA 02139, USA
}

Received 2 April 2006; received in revised form 26 June 2006; accepted 6 July 2006

Available online 23 August 2006

Editor: Scott King

\begin{abstract}
The origin of low-volume, hotspot-like volcanism often observed in continental rift areas is debated, as is the nature of the flow in the mantle beneath. In this paper we assemble seismic constraints on the mantle flow below the Baikal Rift Zone. We combine new evidence from upper-mantle tomography and from a radially anisotropic shear-velocity profile measured beneath and SE of the rift with published shear-wave-splitting constraints on azimuthal anisotropy. Fast directions of azimuthal anisotropy are perpendicular to the rift on both of its sides. Stable Siberian-Platform lithosphere on the northern side extends down to $200 \mathrm{~km}$; on the southern side, the lithosphere is only $60-70 \mathrm{~km}$ thick. This asymmetry, with the thick cratonic root forming a barrier to convective flow, inhibits a mid-ocean-ridge-like flow pattern. The radially anisotropic profile yields evidence for horizontal flow in the upper asthenosphere $(60-100 \mathrm{~km}) \mathrm{SE}$ of the rift but no evidence for vertical flow. These results are consistent with horizontal asthenospheric flow NW to SE perpendicular to the rift, from beneath the thick Siberian towards the thin Baikal-Mongolian lithosphere. When asthenosphere ascends from the 200-km depth beneath the craton to shallower depths beneath the rift, decompression melting of embedded veins of enriched rock can produce the hotspot-like basaltic volcanism observed. The occurrence of such veins of enriched mantle in sub-cratonic asthenosphere has been predicted by geochemical mantle models; we propose that sub-horizontal asthenospheric flow from beneath cratons is a common cause for hotspot-like volcanism in continental rift zones.
\end{abstract}

(C) 2006 Elsevier B.V. All rights reserved.

Keywords: continental rift; mantle flow; anisotropy; hotspot; plume; plum-pudding

\section{Introduction}

Rifting within continents is often accompanied by eruption of basalts that are - similarly to ocean-island basalts (OIB) - enriched in incompatible elements compared to mid-ocean ridge basalts (MORB) [1-7]. Hot

\footnotetext{
* Corresponding author. Tel.: +31 30253 5192; fax: +31 30253 3486.

E-mail address: sergei@geo.uu.nl (S. Lebedev).
}

convection plumes rising from the deep mantle have been invoked to account for the rapid emplacement of flood basalts near rifts [8,9] and for high-volume volcanism such as in the East African rift system $[10,11]$. A more common kind of continental-rift volcanism, however, involves low-volume, scattered, sporadic eruptions [12]. With rift locations determined by pre-existing zones of weakness in the lithosphere $[13,14]$, it is improbable that deep-mantle plumes happen to occur beneath every or even most of the numerous continental-rift zones around 

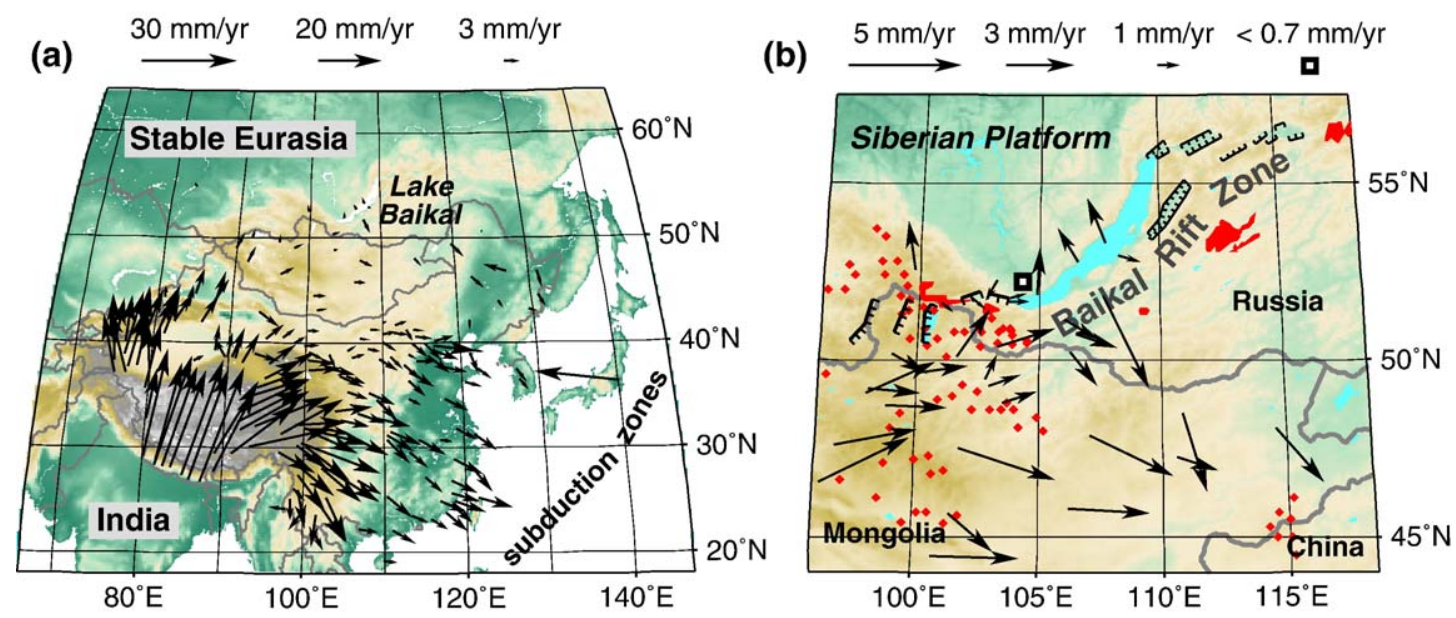

Fig. 1. Surface deformation in Central and Eastern Asia (a) and in the Lake Baikal area (b). GPS-derived velocities are taken from Wang et al. [20] and Calais et al. [21] and plotted with respect to stable Eurasia as defined in [21]. Of the numerous East-Asia-wide measurements (a) we plot only selected, representative ones for clarity. Of the Baikal-Mongolia measurements (b) we plot the most accurate ones that were selected for plotting in [21]. National borders are drawn in gray. Locations of the major Cenozoic volcanic fields (shown in red, b) and of major faults outside Lake Baikal are taken from [22].

the world. In this paper we consider seismic constraints on flow in the mantle beneath the Baikal Rift Zone and argue that it is sub-horizontal asthenospheric flow that may give rise to volcanism in this and perhaps many other rift areas.

The Baikal Rift Zone is located at the boundary of the stable Siberian Platform and deforming Baikal-Sayan fold belt (Fig. 1). Late Cenozoic (30-35 Ma to present) rifting has been accompanied by sporadic basaltic eruptions, with volcanic sites scattered within and around the rift zone [15]. The cause of the rifting has been attributed to the farfield stress associated with the India-Eurasia collision [16]. Occurrence of a deep-mantle plume beneath the rift zone has also been proposed, both as a contributor to the driving forces of the extension (e.g., [17]) and as a supplier of the OIB-like basalts $[18,19]$.

Crustal extension across Lake Baikal is currently $4 \pm 1 \mathrm{~mm} / \mathrm{yr}$, with more extension occurring to the South [21] (Fig. 1b). Estimates of the amount of total extension across the rift range from $\geq 10 \mathrm{~km}$ to $30-40 \mathrm{~km}[23,24]$. The heat flow in the rift zone is only moderately elevated [25]. A hot, large-scale asthenospheric upwelling has been proposed to occur, eroding the lithosphere to crustal thickness below the rift [24], but the lack of widespread melting of the lower crust as well as xenolith evidence are at odds with the presence of such an upwelling [26].

Baikal-Rift tectonics and volcanism have no apparent relation to each other, which suggests that the scale and spatial distribution of volcanic activity are controlled by sublithospheric processes [15]. Convection modeling has produced a variety of plausible patterns of asthenospheric flow below rifts, shaped both by large-scale currents and- in particular for craton-bounded rifts-by small-scale convection [10,27-29]. In order to map the actual mantle flow, observational constraints are needed. Such constraints can be inferred from measurements of seismic anisotropy; because interpretation of these measurements can be nonunique [30] it is useful to combine different types of observations when possible.

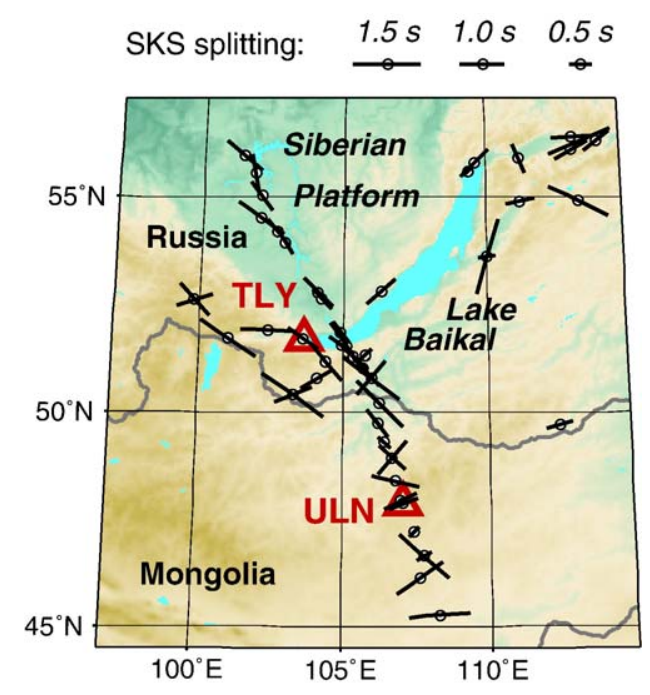

Fig. 2. Shear-wave splitting measurements from [34,35], plotted with lines parallel to the fast polarization direction. Line lengths are proportional to the splitting; the locations of the stations are shown with circles. National borders are drawn with gray lines. Data from the two stations shown as triangles has been used in the interstation dispersion analysis in this study. 
Morgan and Morgan [31] proposed that some of the Cenozoic intraplate volcanism in East Asia is due to a horizontal sublithospheric flow driven by the draining of asthenosphere at Western Pacific subduction zones: subducting slabs drag down a thin layer of asthenosphere; the lost asthenosphere is replaced by means of sublithospheric flow from beneath Asia; in locations where the flow rises (e.g., from beneath thicker continental towards thinner marginal-basin lithosphere) pressure-release melting and volcanism occur. If only enriched "plums" (of the "plum pudding" geochemical mantle model $[32,33]$ ) melt, then the resulting volcanism can be very similar to that observed at hotspots.

Here we present seismic evidence for sub-horizontal asthenospheric flow that we suggest has caused late-
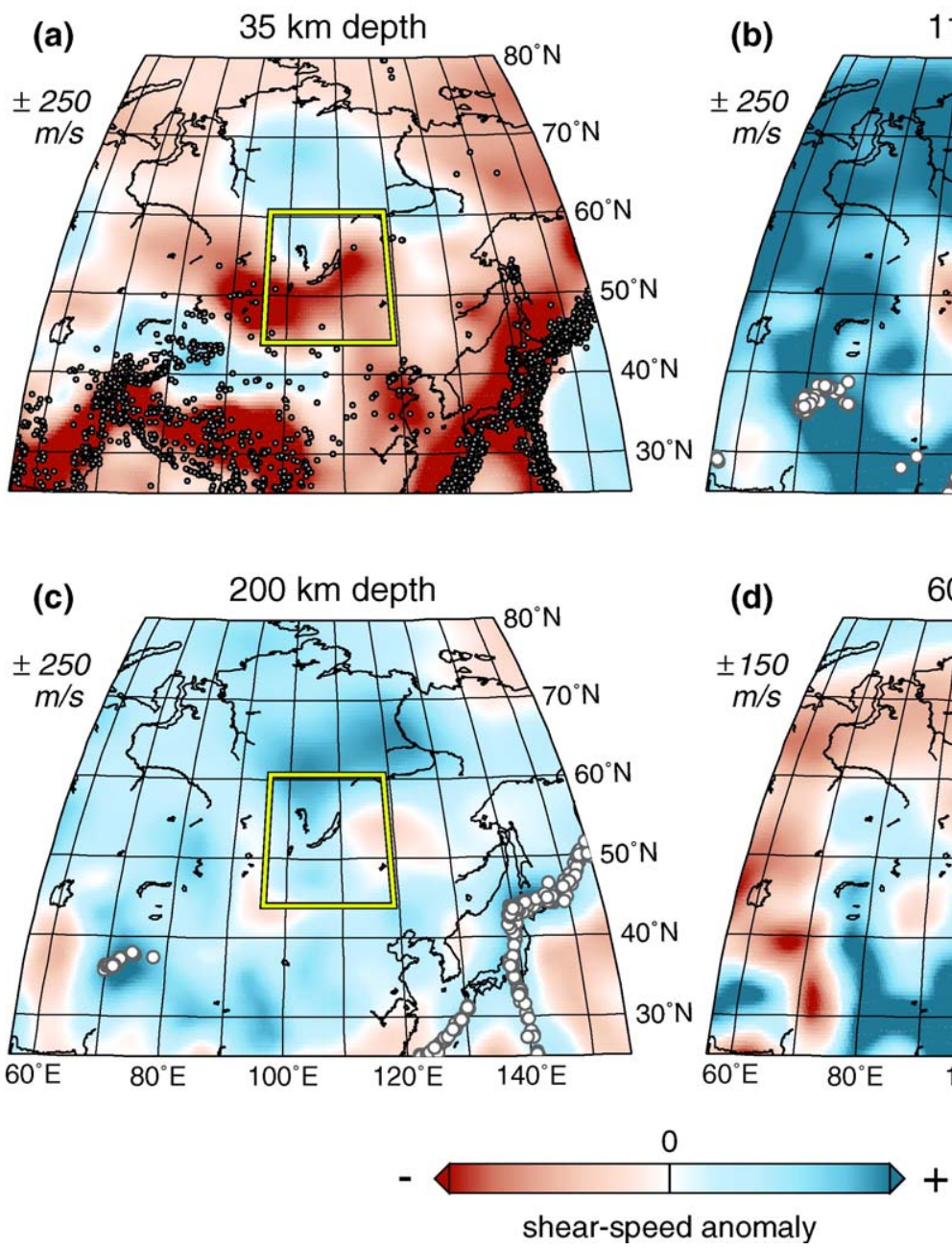

Fig. 3. Horizontal cross-sections through the Asian part of the global tomographic model [36]. The depths and limits of the color scales are given next to the frames. The reference model is the (3-D) CRUST2.0 in the crust and a (1-D) AK135 [38] in the mantle. AK135 was recomputed at a reference period of $50 \mathrm{~s}$ and slowed down by $70 \mathrm{~m} / \mathrm{s}$ in the transition zone. Circles show seismicity at each of the depths [39]. The yellow rectangle is around the Lake Baikal region.
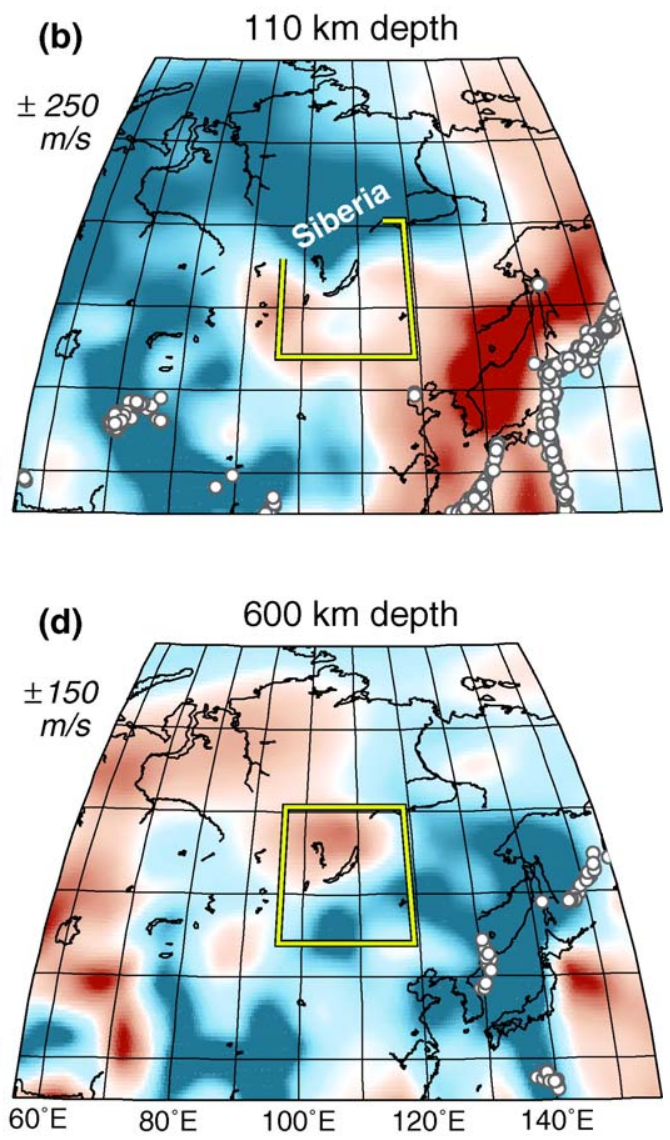

Cenozoic volcanism in the Baikal Rift region. Combining previously published shear-wave splitting measurements, a new shear-speed tomographic model, and a new radially anisotropic shear-velocity profile measured beneath and SE of the rift, we infer that the asthenosphere is flowing perpendicular to the rift from beneath the thick Siberian towards the thin Baikal-Mongolian lithosphere and argue that this is causing the sporadic volcanism observed.

\section{Azimuthal anisotropy: evidence from shear-wave splitting}

A remarkable result of a major seismic experiment in the Baikal Rift area [34,35] was that fast directions of

\section{$+$}

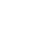


azimuthally anisotropic $S$ waves (measured from $S K S$ splitting) were consistently perpendicular to the rift on both of its sides (with the exception of the rift-parallel measurements in the immediate vicinity of the rift axis) (Fig. 2). This has been interpreted as evidence for a mantle flow beneath the rift similar to that beneath mid-ocean ridges (MOR), with asthenosphere rising vertically beneath the rift axis and then diverging horizontally beneath the lithosphere, in the NW and SE directions away from the axis [34]. The shear-wave splitting observations are, of course, equally consistent with flow in the same NW-to-SE direction on both sides of the rift.

South of the rift, fast anisotropic directions are consistent with (parallel or close to parallel to) GPS-derived velocities of the surface with respect to stable Eurasia (Figs. $1 \mathrm{~b}$ and 2). GPS measurements show present-day motion, whereas seismic anisotropy in the mantle is related to finite strain accumulated over a period of time [30]. For anisotropy in the asthenosphere, the agreement between the two types of measurement is consistent with the lithosphere-asthenosphere relative motion having been perpendicular to the rift axis for a large portion of the rifting period. North of the rift, the Siberian Platform is stationary in the stable-Eurasia reference frame; the pattern of anisotropy is the same on the north and south sides of the axis. A few hundred kilometers SE of the rift, both fast anisotropic directions and GPS-derived velocities change to approximately $\mathrm{W}-\mathrm{E}$.

\section{Upper-mantle heterogeneity}

Seismic tomography can offer constraints on the structure of the lithosphere beneath the region. We consider a global shear-speed model [36] that was derived by means of automated multimode inversion (AMI) of waveforms of surface waves and of regional $S$ and multiple- $S$ waves [37]. Combined sensitivities of the different types of waves yield resolution from the surface down to the bottom of the mantle transition zone (660-km depth).

The background model used in the tomographic inversion is three-dimensional (3-D) in the crust, with the reference crustal structure provided by CRUST2.0 (http:// mahi.ucsd.edu/Gabi/rem.html); lateral shear-speed variations at $35-\mathrm{km}$ depth (Fig. 3a) are given with respect to CRUST2.0 where the Moho depth exceeds $35 \mathrm{~km}$ and with respect to AK135 [38] elsewhere. The tomographic model shows clear contrasts across tectonic boundaries, including subduction zones as well as the Baikal Rift. The contrast between the high velocities within the lithosphere of the Siberian Platform and low velocities beneath BaikalMongolia is even more pronounced at $110 \mathrm{~km}$ depth (in the mantle our background model is a one-dimensional (1-D) depth profile). The seismically fast Siberian lithosphere is observed down to $\sim 200 \mathrm{~km}$ depth. In the transition zone (Fig. 3d) wavespeeds beneath the Baikal region are relatively low, with the lowest values north of the rift. The lateral and vertical extent of the Siberian-Platform lithosphere inferred from our tomography is consistent with inferences from other high-resolution models constrained with surface waves (e.g., [40]); the low-velocity anomaly in the transition zone has been observed in $P$-velocity [41] and $S$-velocity [42] regional studies.

\section{Radially anisotropic structure: evidence from interstation dispersion}

To derive additional constraints on structure southeast of the Baikal Rift, we perform interstation measurements using a pair of stations of the Global Seismographic Network: the station in Talaya (TLY) near the SW tip of the Lake Baikal (approximately on the rift axis) and the station in Ulaanbaatar (ULN) in Mongolia (Figs. 2 and 4). The advantage of two-station measurements compared to source-station ones used in large-scale tomography (Section 3 ) is that they allow one to utilize structural information from fundamental-mode surface waves in broader frequency bands. Surface waves at different periods are sensitive to elastic properties in different depth ranges; measuring Rayleigh- and Love-wave dispersion over broad frequency bands (e.g., in a period range of 10-300 s) enables one to resolve trade-offs between model parameters in the crust and in the upper mantle, both isotropic and radially

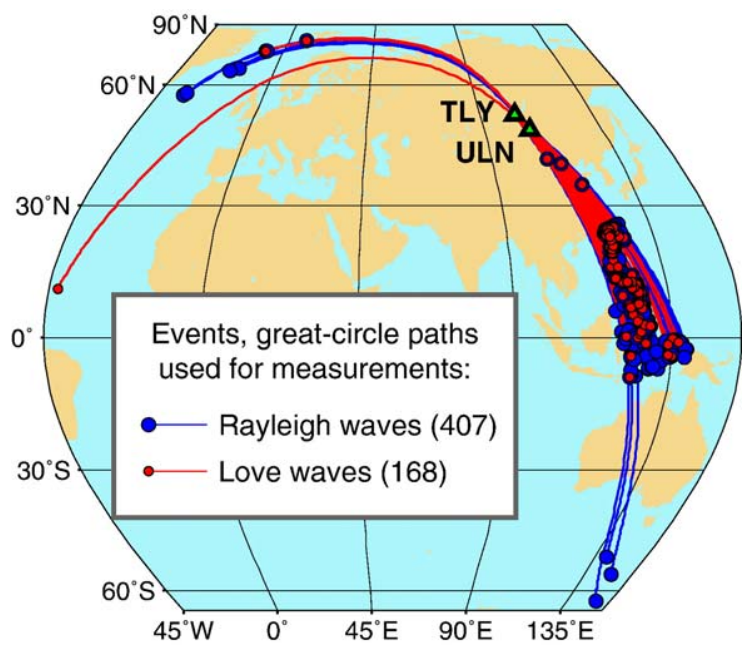

Fig. 4. Great-circle paths from the events used in the interstation dispersion analysis (circles) to the stations TLY and ULN (triangles). The epicenters are plotted overlaying the paths. For some of the events, both Love and Rayleigh waves could be used, for others-only Love or only Rayleigh waves. 
anisotropic. Another advantage of interstation analysis is that when phase-velocity curves are inverted for a shearvelocity profile the inverse problem is small and welldetermined and the trade-offs between structural parameters can be explored with a series of simple tests.

\subsection{Measurement of dispersion curves}

We first measured phase velocities of the fundamentalmode Rayleigh and Love waves by cross-correlating vertical- and transverse-component seismograms from the two stations, as described elsewhere [43]. We also measured average phase velocities between sources and stations by means of waveform inversion with AMI [37], and for each pair of successful measurements (same event, both stations) we calculated phase velocities between the two stations. Because AMI synthesizes complete seismograms, fundamental-mode dispersion could be measured even when the mode interfered with energetic $S$ waves. Due to effects of seismic-wave diffraction some of the automatically measured curves were unrealistically rough. In an interactive curve-selection procedure, we rejected about a quarter (bumpy ones and obvious outliers). In Fig. 5a the discarded curves are shown in pale colors selected ones - in bright colors.

The average Rayleigh- and Love-wave phase-velocity curves and their standard deviations were derived from

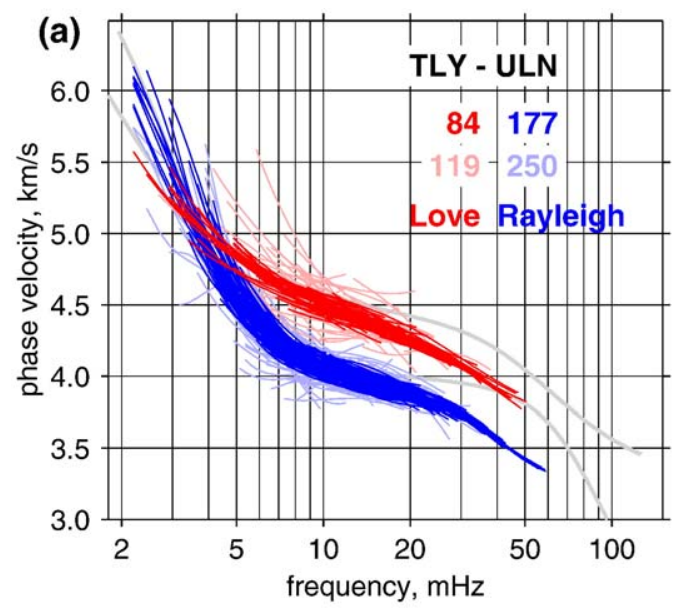

automatic AMI measurements, Rayleigh selected AMI measurements, Rayleigh automatic AMI measurements, Love selected AMI measurements, Love cross-correlation measurements on records from 407 and 168 events, respectively, and from AMI measurements on records from 177 and 84 events. The curves obtained with the two methods overlap over most of their frequency bands and are remarkably consistent (Fig. 5b). Each of the methods performs better than the other at some frequencies, with the cross-correlation, "station-station" technique providing the highest-frequency measurements and the waveform-inversion, "source-station" technique supplying lowest-frequency Love-wave measurements. The combined Rayleigh and Love phase-velocity curves have very wide frequency bands (period range 8-340 s) and small uncertainties, especially at higher frequencies.

\subsection{Radially-anisotropic shear-velocity profile}

We invert the Rayleigh- and Love-wave phasevelocity curves for profiles of vertically and horizontally polarized shear speeds $V_{\text {sv }}$ and $V_{\text {sh }}$, respectively (Fig. 6). The inversion is performed by means of non-linear optimization from the MATLAB toolkit. Synthetic phase velocities are recomputed exactly for every perturbed shear-speed profile during the gradient search. Compressional velocity $V_{\mathrm{p}}$ has a relatively small but not negligible effect on Rayleigh-wave phase velocity; perturbations in $V_{\mathrm{p}}$ were assumed isotropic and coupled to the perturbations in isotropic-average shear speed as

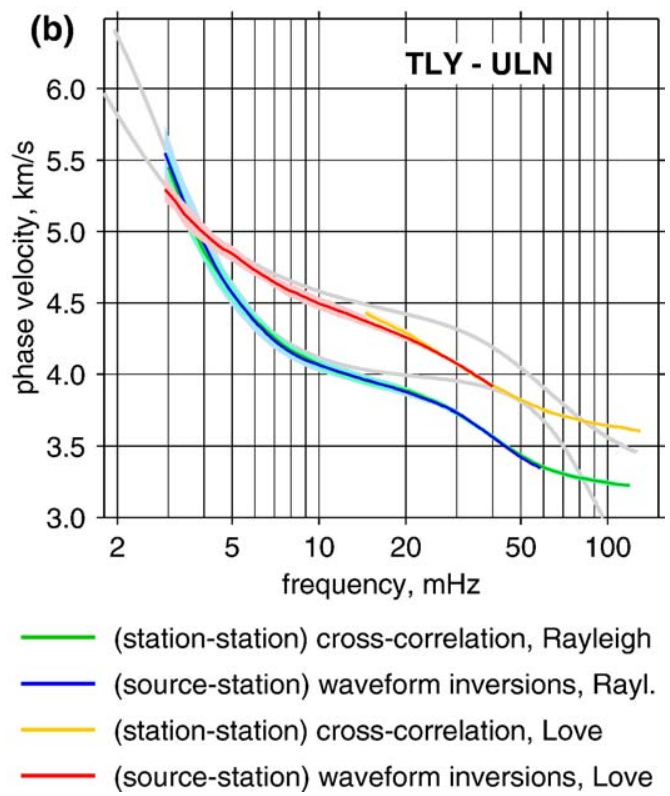

Fig. 5. (a) Measurement of interstation dispersion with the Automated Multimode Inversion of surface- and $S$ wave forms. From pairs of sourcestation measurements (same event, both stations), automatic measurements of interstation phase-velocities are obtained. In an interactive selection that follows, only smooth curves are accepted. (b) The average dispersion curves and their standard deviations from (source-station) AMI measurements are superimposed on those obtained with (station-station) cross-correlation method [43]. Reference curves shown were computed for PREM [44]. 

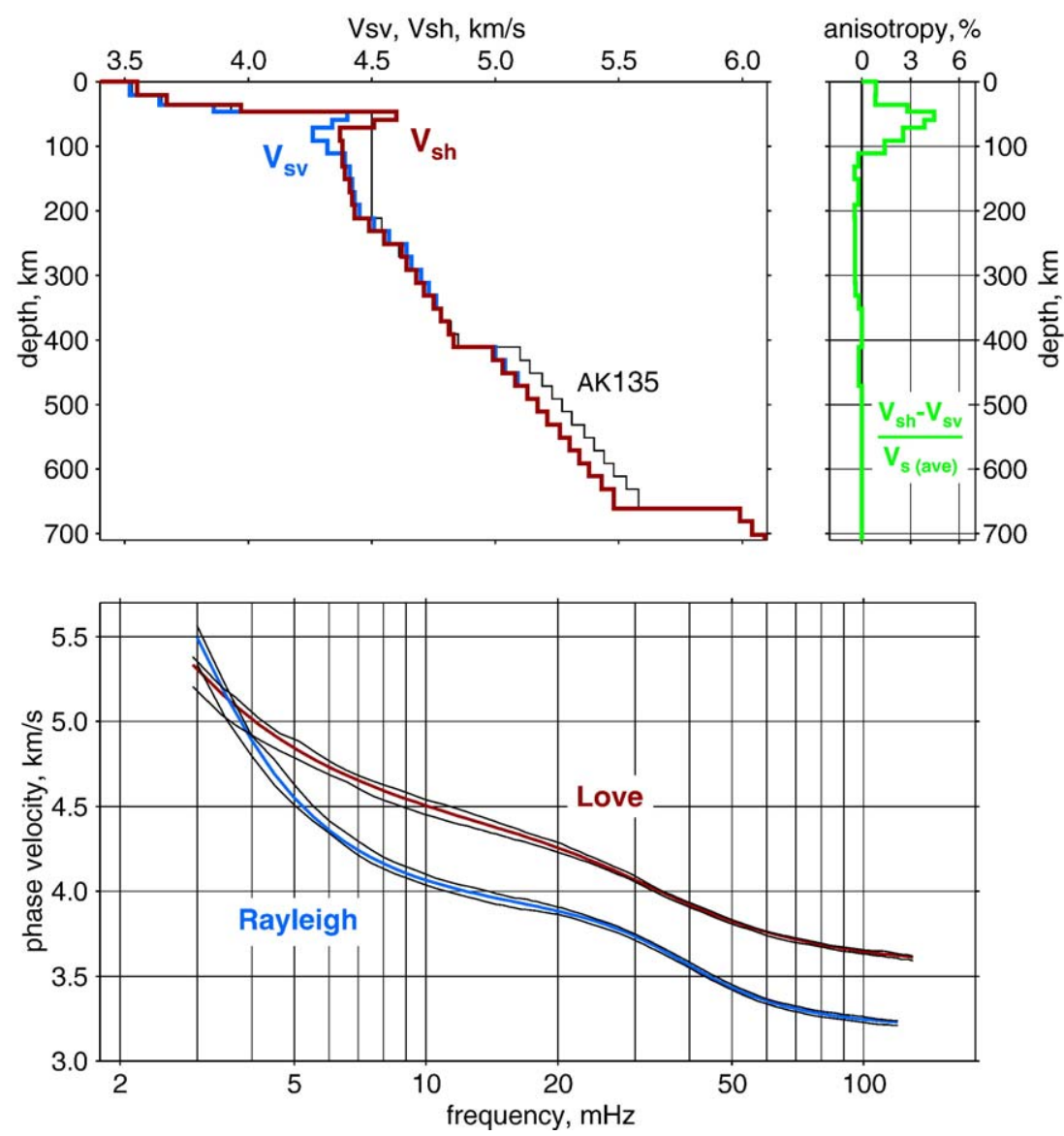

Fig. 6. Our preferred radially-anisotropic $S$-velocity profile, obtained with moderate damping on isotropic and anisotropic anomalies. The corresponding synthetic Love and Rayleigh phase-velocity curves are shown in the bottom frame together with the measured curves plus/minus the error bars.

$\delta V_{\mathrm{p}}(\mathrm{m} / \mathrm{s}) \equiv \delta V_{\mathrm{s}}(\mathrm{m} / \mathrm{s})$ (the main results discussed below do not change if different reasonable coupling definitions are assumed or if no perturbations in $V_{\mathrm{p}}$ are allowed).

The depth to the Moho (crust-mantle interface) was one of the parameters of the inversion. The best-fitting value is in the $45-50 \mathrm{~km}$ range, in agreement with published receiver-function measurements $[45,46]$.

Our preferred model (Fig. 6) was obtained with moderate damping both on isotropic anomalies and on the amount of radial anisotropy. The following features of the model are robust (constrained by the data and not affected by our choice of parameterization and damping). The thin lithosphere south of the rift extends down to $60-70 \mathrm{~km}$ depth and is underlain by a pronounced low-velocity zone, which we interpret to be the low-viscosity asthenosphere. The lower crust, mantle lithosphere, and upper asthenosphere down to $100-110 \mathrm{~km}$ are required to be radially anisotropic, $V_{\mathrm{sh}}$ being 3-4\% larger than $V_{\mathrm{sv}}$. No anisotropy is required below $100 \mathrm{~km}$. In the mantle transition zone (410-660 km depth) shear velocity is $\sim 2 \%$ lower than in AK135.

That these features are required by the data was verified by series of tests in which we tried - unsuccessfully - to match the measurements using models with the features absent. We also tested what anomalies can be consistent with the data while not required by it. In the tests shown in Fig. 7, we tried to force into the models radial anisotropy with first $V_{\mathrm{sh}}<V_{\mathrm{sv}}$ and then $V_{\mathrm{sh}}>V_{\mathrm{sv}}$. Using gradient searches with damping, we looked for models as consistent as possible with the a priori chosen patterns of radial anisotropy $\left(V_{\mathrm{sh}}=V_{\mathrm{sv}}-0.2 \mathrm{~km} / \mathrm{s}\right.$ at all depths and $V_{\mathrm{sh}}=V_{\mathrm{sv}}+0.2 \mathrm{~km} / \mathrm{s}$ at all depths) while also consistent with the measured dispersion curves within error bars. The results show, for example, that radial anisotropy at transition-zone depths is poorly constrained: the models are not inconsistent with the data with either $V_{\mathrm{sh}}<V_{\mathrm{sv}}$ or $V_{\mathrm{sh}}>V_{\mathrm{sv}}$. (The reasons for this are that the 

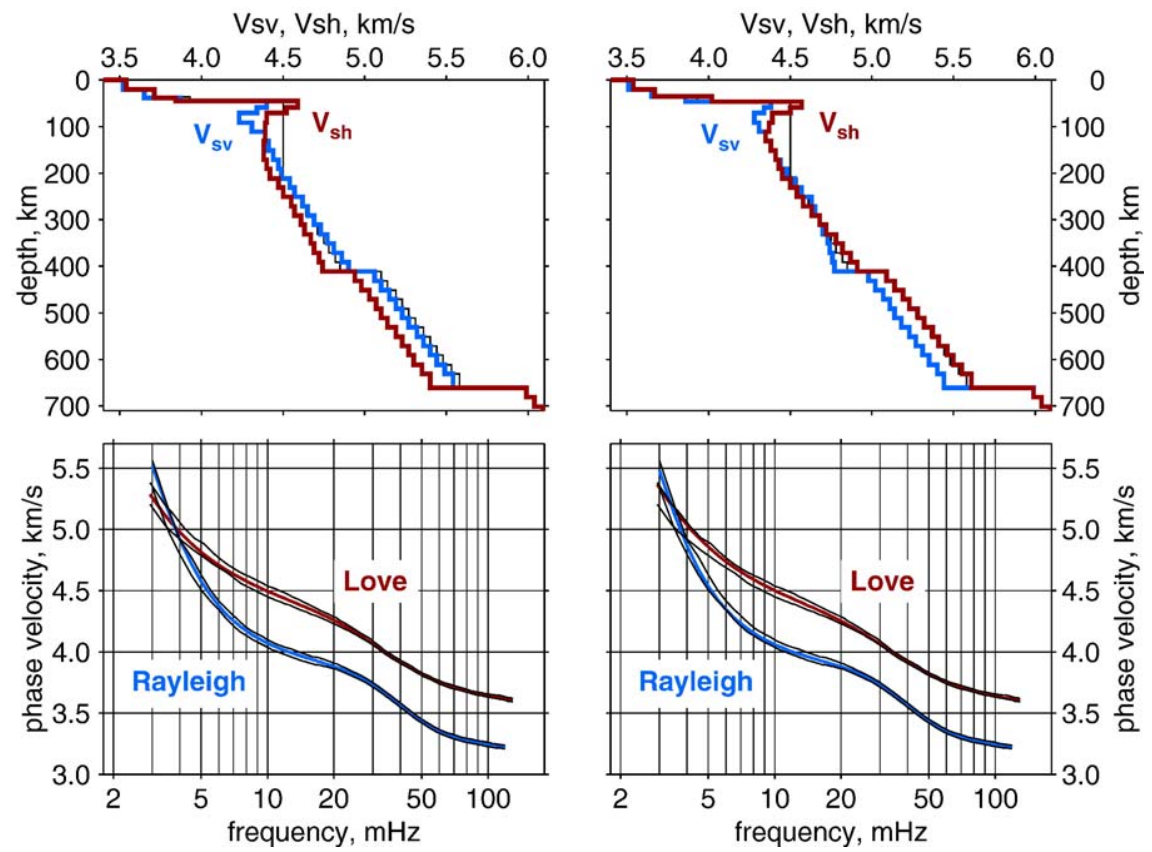

Fig. 7. Tests on forcing patterns of radial anisotropy into the profiles: anisotropic $S$-velocity profiles and the corresponding synthetic Love and Rayleigh phase-velocity curves obtained in inversions that were regularized so as to strongly encourage radial anisotropy in the models with $V_{\mathrm{sv}}>V_{\mathrm{sh}}$ (left) or $V_{\mathrm{sv}}<V_{\mathrm{sh}}$ (right).

Love-wave sensitivity even at longest of our measurement periods weakens by the transition-zone depth and that our error bars at longest periods are relatively large.) In contrast, structure in the upper $150 \mathrm{~km}$ changes little in these and other tests, which confirms that it is tightly constrained by the data.

\section{Seismic structure and mantle flow}

Fast azimuthal-anisotropy directions inferred from shear-wave splitting [34] are consistent with asthenospheric flow perpendicular to the Baikal Rift (Fig. 2). The interpretation is non-unique: the depth interval of the detected anisotropy is unknown and, if the anisotropy is due to asthenospheric flow, the direction of the flow is ambiguous (either NW or SE). We argue that seismological and other observations can be explained by a model in which asthenosphere flows from beneath the Siberian Platform, NW-to-SE across the rift (Fig. 8).

The cratonic lithosphere of the Siberian Platform is likely to have been stable for billions of years, due to its high viscosity, yield strength and compositional buoyancy [48]. Substantial strain within it at present or in the recent past is unlikely. The boundary of the cratonic lithosphere in the mantle thus forms a barrier for convective flow that extends from the surface down to $200 \mathrm{~km}$ depth. The presence of such a barrier just NW of the rift renders unlikely MOR-type mantle flow.

Shear-wave splitting observed on the Siberian Platform probably originates either from frozen anisotropy within the lithosphere or from anisotropy in the asthenosphere beneath it [34]. Frozen lithospheric anisotropy cannot be ruled out on the basis of our observational evidence. It would have to have formed, however, in ancient times and if it was responsible for the observed splitting then the fact that the fast anisotropic directions NW and SE of the rift are identical would have to be a coincidence. We suggest that it is more likely that the observed shear-wave splitting is related to current and recent strain within the asthenosphere beneath the Siberian Platform.

Southeast of the rift axis, the lithosphere is thin $(60-70 \mathrm{~km})$, in contrast with estimates in most previous studies (e.g., [49,41]). Surface-wave observations require strong radial anisotropy within the lithosphere and upper asthenosphere down to $100 \mathrm{~km}$ depth. Within the deforming lithosphere, the anisotropy can be attributed both to present-day deformation and to frozen structure $[30,50,51]$. In the asthenosphere, the $\sim 3 \%$ detected radial anisotropy is probably caused by strain associated with recent horizontal flow.

GPS-derived surface velocities southeast of the rift correlate with fast directions of anisotropy inferred from 


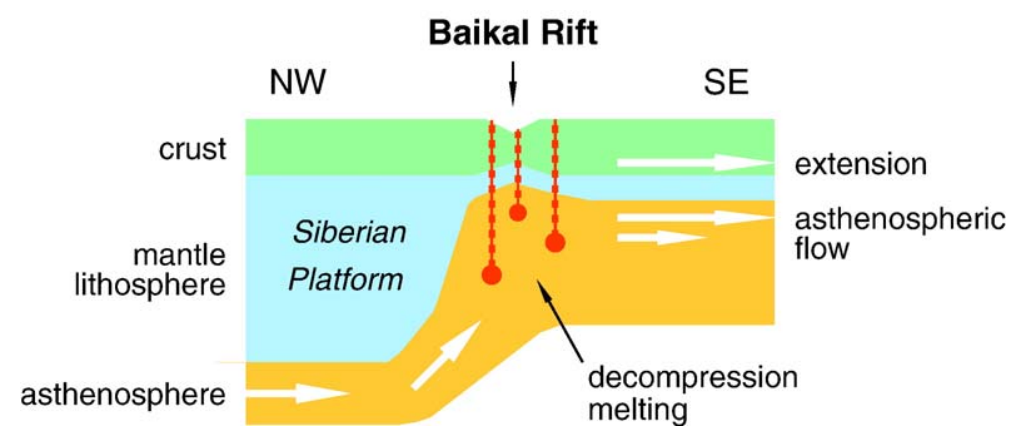

Fig. 8. Interpretative cross-section perpendicular to the Baikal Rift. White arrows show motion with respect to the Siberian Platform lithosphere. Relative velocities of the lithosphere and asthenosphere SE of the rift reflect the scenario in which asthenosphere is dragged by the lithosphere above. In an alternative scenario with asthenospheric flow due to a pressure gradient (e.g., pull towards Western Pacific subduction zones where asthenosphere is entrained by subducting slabs and lost to deep mantle $[31,47])$, the velocity of the asthenosphere can be greater than the velocity of the lithosphere.

shear-wave splitting (Figs. $1 \mathrm{~b}$ and 2). Such correlation is absent in some other locations in the deforming Central and Eastern Asia; this has been interpreted as an indication that the anisotropy sampled by $S K S$ waves is primarily within the lithosphere rather than asthenosphere [50,51]. Fast directions of seismic anisotropy in the asthenosphere, however, cannot be expected to always be parallel to the current direction of the relative lithosphere-asthenosphere motion: they depend on the history of the flow [52]. Given the complex, evolving pattern of rotation of lithospheric blocks near the IndiaEurasia suture, it is to be expected that anisotropic fast directions do not necessarily coincide with surface velocities. Moreover, asthenosphere itself cannot be assumed stationary or disturbed only by the drag from the lithosphere above. It may be stirred by the relative motion of thicker and thinner lithospheric blocks, pushed by mantle upwellings [10], or pulled towards downwellings $[31,47]$.

Possible causes for the rift-perpendicular, NW-to-SE asthenospheric flow in the Baikal region include the drag from the Baikal-Mongolia lithosphere above and the pressure gradient due to draining of asthenosphere at the Western Pacific subduction zones (Fig. 1). Both scenarios are feasible and consistent with observed anisotropy. In the former, the lithospheric extension of a few tens of kilometers across the rift zone [23,24] produces sufficient strain in the asthenospheric layer a few tens of kilometers thick to cause strong anisotropy [30]. In the latter, asthenosphere is pulled SE towards the Western Pacific subduction zones: both the upper (cold) and the lower (hot) sides of slabs drag down a layer of asthenosphere at least a few kilometers thick [47], and the lost asthenosphere is likely to be replaced by flow from beneath Eurasia [31]. The rate of this flow can be greater than the rate of extension across Baikal, implying that drag from asthenosphere may be one of the driving forces of the lithospheric extension.

Volcanism in the Baikal region is low-volume, scattered, and sporadic, with the erupted basalts enriched in incompatible elements $[15,18,19]$. Such volcanism can be produced by melting of enriched "plums" in the asthenosphere beneath the rift area. Small-scale chemical heterogeneities have long been suggested to be ubiquitous in the mantle [32,33,53-56]. Morgan and Morgan [33] have proposed "two-stage melting" to be the basis of the mantle plum-pudding recipe: plume upwellings first melt a small amount at a 100-200 km depth; "plums" are easier to melt, and a large proportion of the incompatible elements goes into the melt which forms enriched OIB; when the depleted leftovers melt again at $20-75 \mathrm{~km}$ depth beneath mid-ocean ridges, depleted MORB is produced.

This mantle plum-pudding recipe [33] implies that asthenosphere beneath $200-\mathrm{km}$ thick cratonic lithosphere may consist of or include material that has not yet undergone the first-stage melting because it had not reached a shallow enough depth. It still contains the enriched "plums" and if it flows from beneath the craton towards the rift and ascends along the bottom of the thinning lithosphere, the "plums" will melt, producing sporadic eruptions of enriched basalts.

In the model of Morgan and Morgan [33], material with enriched veins is brought into the upper mantle by upwellings from the lower mantle (plumes). Shallower origins for small-scale chemical heterogeneity in the upper mantle have also been proposed $[29,57,56]$. Our model (sub-horizontal flow towards rifts resulting in sporadic volcanism) may be compatible with different origins of chemical heterogeneity in the asthenosphere. The flow from beneath thick lithosphere towards rifts is only one element in the complex system of global mantle convection, although one of particular interest because, as 
we propose, it gives rise to rift-zone volcanism observed at the surface.

\section{Conclusions}

The location of the Baikal Rift Zone above the transition from thick Siberian to thin Mongolian lithosphere, the consistent rift-normal pattern of fast directions of azimuthal anisotropy on both sides of the rift, the presence of strong anisotropy within the upper asthenosphere beneath Baikal-Mongolia, and the occurrence of scattered, hotspot-like volcanism in the vicinity of the rift suggest that the flow of asthenosphere is normal to the rift and that its rise from under the Siberian craton causes decompression melting and results in the basaltic volcanism observed.

This mechanism may not be unique to Baikal. Continental rifts, especially those near cratonic boundaries, are locations where sublithospheric flow can move mantle rock from $150-200 \mathrm{~km}$ to shallower $(<100 \mathrm{~km})$ depths. Subcratonic asthenosphere can contain veins of enriched mantle $[33,56]$. We suggest that the flow from beneath cratons and the resulting decompression melting of these veins is the cause of sporadic volcanism in many continental rift zones worldwide.

\section{Acknowledgements}

We thank W. Jason Morgan for the enlightening discussions at the 2005 "Deep Earth" workshop in Frejus. Comments from Greg Houseman and from anonymous referees helped us to improve the manuscript. Figures were generated with Generic Mapping Tools [58]. Waveform data was obtained from facilities of the Incorporated Research Institutions for Seismology (IRIS) Data Management System (DMS), funded through the National Science Foundation (NSF) GEO Directorate, Instrumentation and Facilities Program, under Cooperative Agreement EAR-0004370. Global Seismographic Network (GSN) is operated jointly by the IRIS, the United States Geological Survey (USGS), and the NSF. This work was supported by the VICI Innovative Research Award, awarded by the Netherlands Organization for Scientific Research (NWO) to RvdH.

\section{References}

[1] P.A. Ziegler, European Cenozoic rift system, Tectonophysics 208 (1992) 91-111.

[2] D. Latin, F.G. Waters, Basaltic magmatism in the North Sea and its relationship to lithospheric extension, Tectonophysics 208 (1992) 77-90.
[3] M. Wilson, H. Downes, Mafic alkaline magmatism associated with the European Cenozoic rift system, Tectonophysics 208 (1992) 173-182.

[4] M. Wilson, Z.M. Lyashkevich, Magmatism and the geodynamics of rifting of the Pripyat-Dnieper-Donets rift, East European Platform, Tectonophysics 268 (1996) 65-81.

[5] S.R. Hart, J. Blusztajn, W.E. LeMasurier, D.C. Rex, Hobbs Coast Cenozoic volcanism: implications for the West Antarctic rift system, Chem. Geol. 139 (1997) 223-248.

[6] E.-R. Neumann, E.A. Dunworth, B.A. Sundvoll, J.I. Tollefsrud, B1 basaltic lavas in Vestfold-Jeloya area, central Oslo rift: derivation from initial melts formed by progressive partial melting of an enriched mantle source, Lithos 61 (2002) 21-53.

[7] C. Gautheron, M. Moreira, C. Allegre, He, Ne and Ar composition of the European lithospheric mantle, Chem. Geol. 217 (2005) 97-112.

[8] W.J. Morgan, Convective plumes in the lower mantle, Nature 230 (1971) 42-43.

[9] R. White, D. McKenzie, Magmatism at rift zones: the generation of volcanic continental margins and flood basalts, J. Geophys. Res. 94 (1989) 7685-7729.

[10] C.J. Ebinger, N.H. Sleep, Cenozoic magmatism throughout east Africa resulting from impact of a single plume, Nature 395 (1998) 788-791.

[11] D.S. Weeraratne, D.W. Forsyth, K.M. Fischer, A.A. Nyblade, Evidence for an upper mantle plume beneath the Tanzanian craton from Rayleigh wave tomography, J. Geophys. Res. 108 (2003), doi:10.1029/2002JB002273.

[12] G.E. Lofgren, A.E. Bence, M.B. Duke, M.A. Dungan, J.C. Green, S.E. Haggerty, L.A. Haskin, A.J. Irving, P.W. Lipman, A.J. Naldrett, J.J. Papike, A.M. Reid, J.M. Rhodes, S.R. Taylor, Petrology and chemistry of terrestrial, lunar and meteoritic basalts, in: Basaltic Volcanism Study Project (Ed.), Basaltic volcanism on the terrestrial planets, Pergamon Press, 1981, pp. 1-437.

[13] A.M.C. Sengör, B.A. Nayal'in, Rifts of the world, in: R.E. Ernst, K.L. Buchan (Eds.), Mantle plumes: Their identification through time, no. 352 in Geol. Soc. Am. Spec. Pap., Geol. Soc. Am., Boulder, 2001, pp. 389-482.

[14] A. Tommasi, A. Vauchez, Continental rifting parallel to ancient collisional belts: an effect of the mechanical anisotropy of the lithospheric mantle, Earth Planet. Sci. Lett. 185 (2001) 199-210.

[15] N.A. Logatchev, N.A. Florentsov, The Baikal system of rift valleys, Tectonophysics 45 (1978) 1-13.

[16] P. Molnar, P. Tapponnier, Cenozoic tectonics of Asia: effects of a continental collision, Science 189 (1975) 419-426.

[17] Y.A. Zorin, E.K. Turutanov, V.V. Mordvinova, V.M. Kozhevnikov, T.B. Yanovskaya, A.V. Treussov, The Baikal rift zone: the effect of mantle plumes on older structure, Tectonophysics 371 (2003) $153-173$.

[18] V.V. Yarmolyuk, V.G. Ivanov, V.I. Kovalenko, B.G. Pokrovskii, Magmatism and geodynamics of the southern Baikal volcanic region (mantle hot spot): results of geochronological, geochemical, and isotopic ( $\mathrm{Sr}, \mathrm{Nd}$, and $\mathrm{O})$ investigations, Petrology 11 (2003) 1-30.

[19] J.S. Johnson, S.A. Gibson, R.N. Thompson, G.M. Nowell, Volcanism in the Vitim Volcanic Field, Siberia: geochemical evidence for a mantle plume beneath the Baikal rift zone, J. Petrol. 46 (2005) 1309-1344.

[20] Q. Wang, P.Z. Zhang, J.T. Freymueller, R. Bilham, K.M. Larson, X. Lai, X.Z. You, Z.J. Niu, J.C. Wu, Y.X. Li, J.N. Liu, Z.Q. Yang, Q.Z. Chen, Present-day crustal deformation in China constrained by global positioning system measurements, Science 294 (2001) 574-577. 
[21] E. Calais, M. Vergnolle, V. San'kov, A. Lukhnev, A. Miroshnitchenko, S. Amarjargal, J. Déverchére, GPS measurements of crustal deformation in the Baikal-Mongolia area (1994-2002): implications for current kinematics of Asia, J. Geophys. Res. 108 (2003), doi:10.1029/2002JB002373.

[22] A.I. Kiselev, Volcanism of the Baikal rift zone, Tectonophysics 143 (1987) 235-244.

[23] L.P. Zonenshain, L.A. Savostin, Geodynamics of the Baikal rift zone and plate tectonics of Asia, Tectonophysics 76 (1981) 1-45.

[24] N.A. Logatchev, Y.A. Zorin, V.A. Rogozhina, Baikal rift: Active or passive? - comparison of the Baikal and Kenya rift zones, Tectonophysics 94 (1983) 223-240.

[25] S.V. Lysak, Heat flow variations in continental rifts, Tectonophysics 208 (1992) 309-323.

[26] D. Ionov, Mantle structure and rifting processes in the BaikalMongolia region: geophysical data and evidence from xenoliths in volcanic rocks, Tectonophysics 351 (2002) 41-60.

[27] S.D. King, D.L. Anderson, An alternative mechanism of flood basalt formation, Earth Planet. Sci. Lett. 136 (1995) $269-279$

[28] S.D. King, D.L. Anderson, Edge-driven convection, Earth Planet. Sci. Lett. 160 (1998) 289-296.

[29] J. Korenaga, Mantle mixing and continental breakup magmatism, Earth Planet. Sci. Lett. 218 (2004) 463-473.

[30] P.G. Silver, Seismic anisotropy beneath the continents: probing the depths of geology, Annu. Rev. Earth Planet. Sci. 24 (1996) $385-432$.

[31] W.J. Morgan, J.P. Morgan, Volcanism due to horizontal sublithospheric flow, 4th "Deep Earth: Theory, Experiment and Observation" Research Conference, Lithosphere-Asthenosphere Interaction, Frejus, France, 2005.

[32] J.D. Morris, S.R. Hart, Isotopic and incompatible element constraints on the genesis of island arc volcanics from Cold Bay and Amak Island, Aleutians, and implications for mantle structure, Geochim. Cosmochim. Acta 47 (1983) 2015-2030.

[33] J.P. Morgan, W.J. Morgan, Two-stage melting and the geochemical evolution of the mantle: a recipe for mantle plum-pudding, Earth Planet. Sci. Lett. 170 (1999) 215-239.

[34] S. Gao, P.M. Davis, H. Liu, P.D. Slack, Y.A. Zorin, V.V. Mordvinova, V.M. Kozhevnikov, R.P. Meyer, Seismic anisotropy and mantle flow beneath the Baikal rift zone, Nature 371 (1994) 149-151.

[35] S. Gao, P.M. Davis, H. Liu, P.D. Slack, A.W. Rigor, Y.A. Zorin, V.V. Mordvinova, V.M. Kozhevnikov, N.A. Logatchev, SKS splitting beneath continental rift zones, J. Geophys. Res. 102 (1997) 22781-22797.

[36] S. Lebedev, R.D. van der Hilst, A high-resolution, shear-speed model of the upper mantle, Eos, Trans. AGU 85 (47) (2004) (Fall Meet. Suppl., S52B-07).

[37] S. Lebedev, G. Nolet, T. Meier, R.D. van der Hilst, Automated multimode inversion of surface and $S$ waveforms, Geophys. J. Int. 162 (2005) 951-964

[38] B.L.N. Kennett, E.R. Engdahl, R. Buland, Constraints on seismic velocities in the Earth from traveltimes, Geophys. J. Int. 122 (1995) 108-124.

[39] E.R. Engdahl, R.D. van der Hilst, R. Buland, Global teleseismic earthquake relocation with improved travel times and procedures for depth determination, Bull. Seismol. Soc. Am. 88 (1998) 722-743.
[40] N.M. Shapiro, M.H. Ritzwoller, Monte-Carlo inversion for a global shear velocity model of the crust and upper mantle, Geophys. J. Int. 151 (2002) 88-105.

[41] C. Petit, I. Koulakov, J. Deverchère, Velocity structure around the Baikal rift zone from teleseismic and local earthquake traveltimes and geodynamic implications, Tectonophysics 296 (1998) $125-144$.

[42] W. Friederich, The $S$-velocity structure of the East Asian mantle from inversion of shear and surface waveforms, Geophys. J. Int. 153 (2003) 88-102.

[43] T. Meier, K. Dietrich, B. Stockhert, H.P. Harjes, One-dimensional models of shear wave velocity for the eastern Mediterranean obtained from the inversion of Rayleigh wave phase velocities and tectonic implications, Geophys. J. Int. 156 (2004) 45-58.

[44] A.M. Dziewonski, D.L. Anderson, Preliminary reference Earth model, Phys. Earth Planet. Inter. 25 (1981) 297-356.

[45] Y.A. Zorin, V.V. Mordvinova, E.K. Turutanov, B.G. Belichenko, A.A. Artemyev, G.L. Kosarev, S.S. Gao, Low seismic velocity layers in the Earth's crust beneath Eastern Siberia (Russia) and Central Mongolia: receiver function data and their possible geological implication, Tectonophysics 359 (2002) 307-327.

[46] S.S. Gao, K.H. Liu, C. Chen, Significant crustal thinning beneath the Baikal rift zone: new constraints from receiver function analysis, Geophys. Res. Lett. 31 (2004), doi:10.1029/2004GL020813.

[47] J. Hasenclever, J.P. Morgan, M. Hort, Implications of a plumefed asthenosphere layer for mantle flow and mid-ocean ridge melting processes, Eos, Trans. AGU 86 (52) (2005) (Fall Meet. Suppl., T23A-0522).

[48] N.H. Sleep, Evolution of the continental lithosphere, Annu. Rev. Earth Planet. Sci. 33 (2005) 369-393.

[49] Y.A. Zorin, V.M. Kozhevnikov, M.R. Novoselova, E.K. Turutanov, Thickness of the lithosphere beneath the Baikal rift zone and adjacent regions, Tectonophysics 168 (1989) 327-337.

[50] P. Davis, P. England, G. Houseman, Comparison of shear wave splitting and finite strain from the India-Asia collision zone, J. Geophys. Res. 102 (1997) 27511-27522.

[51] L.M. Flesch, W.E. Holt, P.G. Silver, M. Stephenson, C.-Y. Wang, W.W. Chan, Constraining the extent of crust-mantle coupling in central Asia using GPS, geologic, and shear wave splitting data, Earth Planet. Sci. Lett. 238 (2005) 248-268.

[52] E. Kaminski, N.M. Ribe, Timescales for the evolution of seismic anisotropy in mantle flow, Geochem. Geophys. Geosyst. 3 (2002), doi:10.1029/2001GC000222.

[53] G.F. Davies, Earth's neodymium budget and structure and evolution of the mantle, Nature 290 (1981) 208-213.

[54] N.H. Sleep, Tapping of magmas from ubiquitous mantle heterogeneities: an alternative to mantle plumes? J. Geophys. Res. 89 (1984) 10029-10041.

[55] A. Zindler, H. Staudigel, R. Batiza, Isotope and trace element geochemistry of young Pacific seamounts: implications for the scale of upper mantle heterogeneity, Earth Planet. Sci. Lett. 70 (1984) $175-195$.

[56] A. Meibom, D.L. Anderson, The statistical upper mantle assemblage, Earth Planet. Sci. Lett. 217 (2003) 123-139.

[57] D.L. Anderson, Lithosphere, asthenosphere and perisphere, Rev. Geophys. 33 (1995) 125-149.

[58] P. Wessel, W.H.F. Smith, New version of the Generic Mapping Tools released, Eos, Trans. AGU 76 (1995) 329. 